\title{
Comportamento dos pais e comportamento alimentar da criança: Revisão Sistemática
}

\author{
Family influence on children's eating behavior: A Systematic Review
}

Influencia familiar en la conducta alimentaria en niños: Revisión Sistemática

Como citar este artigo:

Santos, Kelly de Freitas; Coelho, Luana Vital, Romano, Márcia Christina Caetano. Comportamento dos pais e comportamento alimentar da criança: Revisão Sistemática Revista Cuidarte. 2020;11(3):e1041.

http://dx.doi.org/10.15649/cuidarte.1041

\section{Revista Cuidarte}

Rev Cuid. 2020; 11(3): e1041

doi) http://dx.doi.org/10.15649/cuidarte.1041

E-ISSN: 2346-3414

(1) Kelly de Freitas Santos 1

(1) Luana Vital Coelho 2

(1) Márcia Christina Caetano Romano

1 Universidade Federal de São João Del-Rei, Campus CCO- Dona Lindu. Sebastião Gonçalves Coelho, 400 Chanadour 35501-296 Divinópolis, MG - Brasil. Autor de Correspondência. E-mail Kellyfreitass83@hotmail. com

2 Universidade Federal de São João Del-Rei, Campus CCO- Dona Lindu. Sebastião Gonçalves Coelho, 400 Chanadour35501-296 Divinópolis, MG - Brasil. E-mail luanavitalcoelho@ yahoo.com.br

3 Universidade Federal de São João Del-Rei, Campus CCO- Dona Lindu. Sebastião Gonçalves Coelho, 400 Chanadour35501-296 Divinópolis, MG - Brasil. E-mail marciachristinacs@ ufsj.edu.br

\section{Resumo}

Introdução: O tema comportamento alimentar tem tido destaque na atualidade em função da implicação deste sobre a determinação de doenças crônicas. São escassos estudos nacionais sobre os determinantes do comportamento alimentar infantil, especialmente no que tange as práticas parentais. Objetivo: identificar a relação entre o comportamento dos pais durante a refeição e comportamento alimentar da criança. Materiais e Métodos: Revisão sistemática da literatura baseada na estratégia PECOS e no PRISMA. Realizou-se a pesquisa nas bases de dados Lilacs, MEDLINE e IBECS, com artigos publicados entre 2013 e 2018. Vinte e três estudos compuseram a presente revisão. Resultados: Dos estudos, 83\% permitiram observar diretamente as práticas parentais durante a refeição, encontrando associação estatisticamente significativa entre o uso de pressão para alimentar pelos pais e alimentação seletiva pela criança. Dentre os estudos, $17 \%$ mostraram que o comportamento alimentar dos pais interfere no comportamento alimentar das crianças, tornando-os similares. A maioria dos artigos são internacionais, sendo apenas um realizado no Brasil. Discussão: O ambiente familiar pode ser considerado um importante formador do comportamento e estilo de vida das crianças. Acredita-se que o contexto familiar contribui para preferências, rejeições e comportamentos alimentares. As crianças aprendem não apenas vivenciando suas próprias experiências, mas observado aos outros. Conclusão: Os dados resultantes desta revisão sistemática permitem evidenciar que as práticas parentais utilizadas pelos pais podem determinar o comportamento alimentar de crianças. Estudos nacionais sobre o comportamento alimentar infantil são imperativos, visando uma maior elucidação sobre o tema e ampliando os fatores relacionados.

Palavras chave: Comportamento Alimentar; Criança; Família; Psicología

Recibido: octubre 29 de 2019

Aceito: mayo 22 de 2020

Publicado: septiembre 1 de 2020 $\square *$ Correspondência kelly Freitas Santos E-mail: kellyfreitass83@hotmail.com 


\title{
Family influence on children's eating behavior: A Systematic Review
}

\begin{abstract}
Introduction: Eating behavior has increasingly gained relevance in recent times given its incidence in identifying chronic diseases. In addition, few studies have been conducted nationwide on the determinants of eating behavior in children, particularly those related to parental feeding practices. Objective: To identify the relationship between parental feeding practices and children's eating behavior. Materials and Methods: A systematic literature review was conducted on PICO and PRISMA strategies. The research was conducted using the LILACS, MEDLINE and IBECS databases, involving articles published between 2013 and 2018. A total of 23 studies make up this review. Results: $83 \%$ of the studies allowed direct observation of parental mealtime practices resulting in a statistically significant association between parental pressure to eat and selective eating in children. $17 \%$ of the studies suggested that parental feeding practices interfere with children's eating behavior, which makes them very similar. Most of the articles have been published worldwide with only one being conducted in Brazil. Discussion: Family settings are considered to contribute to eating preferences, refusals and behaviors. Children learn not only by living their own experiences but also by observing others. Conclusion: The data obtained from this systematic review demonstrate that parental feeding practices can determine eating behavior in children. Further national research on children's eating behavior is essential to better understand and explore its determinants.
\end{abstract}

Key words: Feeding Behavior; Child; Family; Psychology

\section{Influencia familiar en la conducta alimentaria en niños: Revisión Sistemática}

\section{Resumo}

Introducción: La conducta alimentaria ha venido ganando relevancia recientemente debido a su incidencia en la identificación de enfermedades crónicas. Asimismo, se han realizado muy pocos estudios a nivel nacional sobre los factores determinantes de la conducta alimentaria en niños, especialmente lo relacionado con las prácticas de alimentación de los padres. Objetivo: Identificar la relación entre las prácticas de los padres a la hora de comer y la conducta alimentaria del niño. Materiales y Métodos: Se realizó una revisión sistemática de la literatura basada en las estrategias PICO y PRISMA. La investigación se realizó en las bases de datos LILACS, MEDLINE e IBECS, con artículos publicados entre 2013 y 2018.23 estudios componen en total la presente revisión. Resultados: En el $83 \%$ de los estudios se permitió observar directamente las prácticas de los padres durante las comidas y se encontró una asociación estadísticamente significativa entre el uso de la presión para dar de comer por parte de los padres y la alimentación selectiva en los niños. Entre los estudios, el 17 \% demostró que el comportamiento alimenticio de los padres interfiere con la conducta alimentaria de los niños, lo que los vuelve muy similares. La mayoría de los artículos se han publicado internacionalmente y solo uno ha sido realizado en Brasil. Discusión: El entorno familiar puede considerarse un importante formador del comportamiento y del estilo de vida de los niños. Se considera que el contexto familiar contribuye a las preferencias, rechazos y conductas alimentarias. Los niños aprenden no solo viviendo sus propias experiencias, sino también observando las de los demás. Conclusión: Los datos obtenidos en esta revisión sistemática demuestran que las prácticas parentales pueden determinar la conducta alimentaria en niños. A fin de comprender mejor esta temática y profundizar en sus factores asociados, es fundamental llevar a cabo más estudios a nivel nacional sobre la conducta alimentaria en los niños.

Palabras clave: Conducta Alimentaria; Niño; Família; Psicologia 


\section{Introdução}

O comportamento alimentar é representado por todas as formas de convívio com o alimento, envolvendo desde a preferência até a ingestão, representando não somente o que comemos, mas os demais elementos relacionados a isso, como o ambiente da alimentação, a forma e o tempo com que se alimenta e os motivos pelos quais as pessoas comem?. No campo da alimentação e nutrição, o comportamento alimentar aparece, na maioria das vezes, relacionado aos aspectos psicológicos da ingestão de comida, podendo também ser conceituado como práticas individuais e coletivas em relação ao ato de comer. A repetição de um determinado comportamento alimentar pode influenciar na formação de hábitos adequados ou não para a saúde ${ }^{2,3}$.

O tema comportamento alimentar tem tido relevância na atualidade em função das implicações deste sobre a determinação de doenças crônicas prevalentes como diabetes mellitus, obesidade, hipertensão arterial sistêmica, entre outras ${ }^{4}$. Tem-se percebido uma rápida mudança no comportamento alimentar das crianças, com a piora da qualidade da dieta infantil de forma global, caracterizada por uma diminuição no consumo de frutas, legumes e fibras e aumento no consumo de alimentos processados ricos em açúcar, gordura saturada e sódio ${ }^{5}$. No Brasil, estimativas indicam que 47 a $65 \%$ das crianças consomem dieta de baixa qualidade ou intermediária para alimentos ou nutrientes ${ }^{6}$.

Destaca-se, por exemplo, que o comportamento compulsivo frente à alimentação favorece a exacerbação da ingesta calórica, ocasionando o excesso de peso 7 . Além disso, em Pelotas, estudo com crianças de seis a dez anos demonstrou que participantes com comportamentos alimentares em que há interesse excessivo pela comida tiveram mais chance de desenvolver excesso de peso nessa faixa etária8.

Acredita-se que o comportamento alimentar infantil é multideterminado. Elementos inatos, contexto familiar e escolar, questões socioeconômicas e culturais podem se relacionar com o comportamento alimentar da criança ${ }^{4}$.

Estudos, especialmente os internacionais, têm discutido o comportamento alimentar de pais e filhos. As práticas parentais de controle, pressão, recompensa utilizadas pelos pais, por exemplo, parecem influenciar o comportamento alimentar das crianças, podendo aumentar ou diminuir a ingesta de alimentos. Essas investigações, no entanto, são em contextos internacionais e não consideram o comportamento dos pais durante as refeições, o aleitamento materno e condições socioeconômicas ${ }^{8,9}$, tornando oportuna uma investigação sobre o tema.

Nesse sentido, a pesquisa busca responder à pergunta: há associação entre comportamento alimentar dos pais durante a refeição e comportamento alimentar das crianças? 
O estudo tem como objetivo identificar, na literatura atual, a relação entre comportamento dos pais durante a refeição e comportamento alimentar de crianças. A presente investigação poderá contribuir para o desvelamento da questão, aprimorando a literatura sobre o tema, além de trazer indicadores para prevenção de agravos decorrentes do comportamento alimentar inadequado.

\section{Materiais e Métodos}

Trata-se de uma revisão sistemática da literatura, um tipo de pesquisa que disponibiliza um resumo das evidências relacionadas a uma estratégia de intervenção específica, mediante a aplicação de métodos explícitos e sistematizados de busca, apreciação crítica e síntese da informação selecionada9,10. A pergunta de pesquisa foi elaborada conforme a estratégia PECOS, sendo $\mathrm{P}$ referente à crianças, E pertinente aos fatores ambientais/psicológicos, $\mathrm{C}$ comparação entre o comportamento alimentar da criança e práticas parentais e, $\mathrm{O}$ "outcomes" equivalente ao comportamento alimentar ${ }^{11}$. Os artigos selecionados na presente revisão foram pesquisados nas bases de dados Lilacs (Literatura Latino-Americana e do Caribe em Ciências da Saúde), MEDLINE (Medical LiteratureAnalysisandRetrieval System Online) e Ibecs (Índice Bibliográfico Espanhol de Ciências da Saúde). Utilizaram-se os portais PubMed (US National Library of Medicine Nationallnstitutesof Health) e BVS (Biblioteca Virtual em Saúde). Os descritores integram a lista de Descritores em Ciências da Saúde (DeCs) e da Medical SubjectHeadings (MeSH)A busca bibliográfica foi feita utilizando-se o operador booleano AND. Realizaram-se as seguintes combinações em português: (Comportamento alimentar AND criança AND família) AND (Comportamento alimentar AND psicologia AND criança); e em inglês: (Feedingbehavior AND child AND fammily) AND (Feedingbehavior AND Psychology AND child). Consecutivamente, utilizaram-se os critérios de inclusão: artigos publicados em português e inglês entre $1^{\circ}$ de janeiro de 2013 a 31 de dezembro de 2019, sendo esta a data da última busca realizada; faixa etária entre um e cinco anos de idade, caracterizando a primeira infância ${ }^{12}$. Definiu-se o período cronológico para a inclusão dos estudos com a finalidade de investigar os dados mais atualizados da temática.

Analisaram-se publicações pesquisadas crítica e independentemente por dois autores $\mathrm{S}$ e $\mathrm{C}$. As indecisões referentes à seleção dos artigos foram avaliadas em plenária com a participação de um terceiro pesquisador, até se obter concordância. O processo de seleção dos artigos seguiu o Protocolo PRISMA (Preferred Reporting Items for Systematic Reviews and Meta-Analyses), para o processo de identificação, seleção, elegibilidade e inclusão dos estudos ${ }^{13}$.

Para classificar o nível de evidência dos artigos, foi utilizada a categorização da Agency for Health care Research and Quality (AHRQ), segundo a qual o nível 1 é considerado o de maior força de evidência, no qual são incluídas as metanálises de múltiplos estudos controlados. Projetos individuais com desenho experimental, como os ensaios clínicos aleatórios, são considerados de nível 2. Estudos de coorte, caso-controle e quase experimentais, como estudos não randomizados, são classificados como nível 3. Estudos com desenho não experimental, como os transversais, recebem o nível de evidência 4. Relatórios de caso são considerados nível 5, e opiniões de autoridades respeitáveis baseadas na competência clínica ou opinião de comitês de especialistas e interpretações de informações não baseadas em pesquisas estão no nível $6^{13}$. 


\section{Resultados}

A pesquisa pelos descritores, de acordo com as combinações citadas, resultou na identificação inicial de 1.446 artigos. Na seleção, retiraram-se quatro artigos repetidos. Posteriormente ao uso dos filtros ou limites, foram excluídos 1.388 trabalhos e, por meio da leitura dos títulos e resumos, permaneceram 54 artigos elegíveis. Foi realizada a leitura minuciosa e integral de 54 artigos elegíveis, dos quais 31 foram excluídos por não responderem à questão da pesquisa. Ao final, foram incluídos 23 estudos que respondiam à questão norteadora desta investigação (Figura 1).

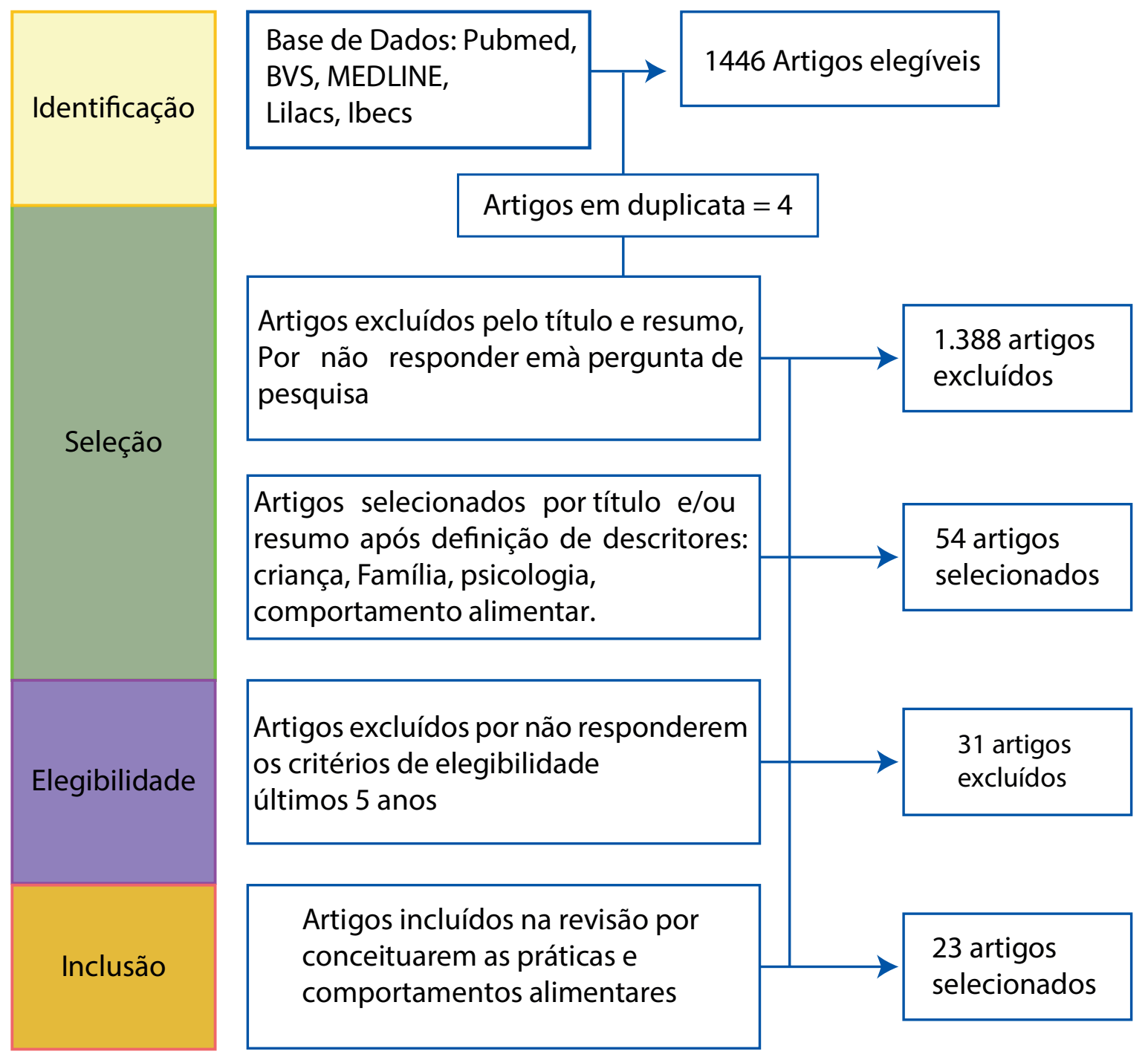

Figura 1. Fluxograma da pesquisa: identificação, seleção, elegibilidade e inclusão dos artigos científicos na revisão sistemática, de acordo com guidelinePRISMA (MOHER et al., 2009).

Os 23 artigos selecionados constituíam $12(52,2 \%)$ estudos de delineamento transversal, quatro $(17,4 \%)$ de revisão sistemática, cinco $(21,7 \%)$ de coorte,e dois $(8,7 \%)$ longitudinais experimentais. Os estudos apresentaram amostras que somadas incluíram 37.921 crianças investigadas. Dentre os 23 artigos desta revisão, 22 eram internacionais e apenas um nacional (Quadro1). 
Quadro 1. Caracterização dos estudos incluídos na revisão sistemática, n=23, 2019.

\begin{tabular}{|c|c|c|c|c|c|c|}
\hline $\begin{array}{l}\text { Referência/ } \\
\text { Ano de } \\
\text { Publicação/ } \\
\text { País }\end{array}$ & Local & $\begin{array}{l}\text { Popul ação/ amostra/ } \\
\text { Faixa etária }\end{array}$ & $\begin{array}{l}\text { Delineamento } \\
\text { do estudo }\end{array}$ & $\begin{array}{l}\text { Nível de } \\
\text { evidência } \\
\text { científica }\end{array}$ & $\begin{array}{l}\text { Instrumento de avaliação } \\
\text { das práticas e comportamento } \\
\text { dos pais e das crianças }\end{array}$ & $\begin{array}{l}\text { Principais } \\
\text { Resultados }\end{array}$ \\
\hline $\begin{array}{l}\text { Susan } \\
\text { et al, } \\
2014^{14}\end{array}$ & Inglaterra & $\begin{array}{l}\text { Crianças na faixa etária entre } 3 \text { a } 6 \\
\text { anos de idade, uma amostra } N= \\
439\end{array}$ & Transversal & Nível 4 & $\begin{array}{l}\text { Questionário de Comportamento } \\
\text { Alimentar das Crianças (CEBQ) e } \\
\text { Questionário de alimentação infantil } \\
\text { (CFQ) }\end{array}$ & $\begin{array}{l}\text { Restrição e monitoramento } \\
\text { alimentar: Associação direta } \\
\text { Recompensa alimentar: Não } \\
\text { houve associação com o } \\
\text { comportamento alimentar das } \\
\text { crianças }\end{array}$ \\
\hline $\begin{array}{l}\text { Palfreyman } \\
\text { et al, } \\
2014^{33}\end{array}$ & $\begin{array}{l}\text { Inglaterra, } \\
\text { Ásia e } \\
\text { Europa }\end{array}$ & $\begin{array}{l}\text { Crianças com idade entre } 18 \\
\text { meses e } 8 \text { anos, amostra } \mathrm{N}=497\end{array}$ & Transversal & Nível 4 & $\begin{array}{l}\text { Práticas Abrangentes de } \\
\text { Alimentação Questionário (CFPQ) e } \\
\text { Questionário de Frequência } \\
\text { Alimentar (QFA) }\end{array}$ & $\begin{array}{l}\text { Associação direta com as } \\
\text { práticas parentais de pressão } \\
\text { alimentar com uso de força } \\
\text { física, restrição, recompensa e } \\
\text { monitoramento alimentar. }\end{array}$ \\
\hline $\begin{array}{l}\text { Antoniou } \\
\text { et al, } \\
2015^{25}\end{array}$ & Holanda & $\begin{array}{l}\text { Amostra inicial de } \mathrm{N}=2814 \text { mães } \\
\text { grávidas. As mães foram convida- } \\
\text { das a preencher um questionário } \\
\text { sobre o estilo de alimentação de } \\
\text { seus filhos ( } \mathrm{n}=2037 \text { ) quando as } \\
\text { crianças tinham } 5 \text { anos de idade e } \\
\text { em acompanhamento questio- } \\
\text { nários em momentos com idade } \\
\text { média de } 7,8 \text { e } 9 \text { anos, respectiva- } \\
\text { mente. }\end{array}$ & $\begin{array}{l}\text { Coorte } \\
\text { prospectivo }\end{array}$ & Nível 3 & $\begin{array}{l}\text { Questionário de Estilos de } \\
\text { Alimentação dos Cuidadores (CFSQ) } \\
\text { e Questionário de alimentação } \\
\text { infantil (CFQ). }\end{array}$ & $\begin{array}{l}\text { Associação direta com as } \\
\text { práticas parentais de pressão } \\
\text { alimentar com uso de força } \\
\text { física, restrição, recompensa e } \\
\text { monitoramento alimentar. }\end{array}$ \\
\hline $\begin{array}{l}\text { Remy } \\
\text { et al, } \\
2015^{29}\end{array}$ & Finlândia & $\begin{array}{l}\text { Crianças em idade pré-escolar ( } 3 \text { a } 6 \\
\text { anos de idade), uma amostra } \\
N=236 \text { crianças }\end{array}$ & Experimental & Nível 2 & $\begin{array}{l}\text { Questionário de Práticas } \\
\text { Abrangentes de Alimentação (CFPQ) } \\
\text { e Questionário de Comportamento } \\
\text { Alimentar das Crianças (CEBQ). }\end{array}$ & $\begin{array}{l}\text { Recompensa alimentar: } \\
\text { Associação com direta com o } \\
\text { comportamento alimentar da } \\
\text { criança }\end{array}$ \\
\hline $\begin{array}{l}\text { Russell } \\
\text { et al, } \\
2015^{27}\end{array}$ & Austrália & $\begin{array}{l}\text { Crianças na faixa etária entre } 2 \text { a } 5 \\
\text { anos de idade, uma amostra } \mathrm{N}= \\
371\end{array}$ & Transversal & Nível 4 & $\begin{array}{l}\text { Escala de Neofobia Alimentar } \\
\text { Infantil (CFNS), Índice de Preferência } \\
\text { Saudável (HPI) e Questionário } \\
\text { semiestruturado sobre preferência } \\
\text { de comida pela criança. }\end{array}$ & $\begin{array}{l}\text { Recompensa alimentar e } \\
\text { modelagem parental: } \\
\text { Associação direta }\end{array}$ \\
\hline $\begin{array}{l}\text { Hoffmann } \\
\text { et al, } \\
2016^{22}\end{array}$ & $\begin{array}{l}\text { Estados } \\
\text { Unidos }\end{array}$ & $\begin{array}{l}\text { Crianças na faixa etária de } 7 \text { a } 11 \\
\text { anos de idade, amostra } n=192\end{array}$ & Transversal & Nível 4 & $\begin{array}{l}\text { Questionário Escolha de alimento } \\
\text { (FCQ), Questionário de Práticas } \\
\text { Abrangentes de Alimentação } \\
\text { (CFPQ), e Questionário de } \\
\text { Frequência Alimentar (QFA). }\end{array}$ & $\begin{array}{l}\text { Restrição e recompensa } \\
\text { alimentar: Associação direta }\end{array}$ \\
\hline $\begin{array}{l}\text { Anna Ek } \\
\text { et al, } \\
2016^{25}\end{array}$ & Suécia & $\begin{array}{l}\text { Crianças na faixa etária entre } 3 \text { a } 8 \\
\text { anos de idade, amostra } \mathrm{N}=432\end{array}$ & Transversal & Nível 4 & $\begin{array}{l}\text { Questionário de Comportamento } \\
\text { Alimentar das Crianças (CEBQ), } \\
\text { Questionário de alimentação infantil } \\
\text { (CFQ) }\end{array}$ & $\begin{array}{l}\text { Pressão alimentar com o uso de } \\
\text { força física e restrição alimentar: } \\
\text { Associação direta }\end{array}$ \\
\hline $\begin{array}{l}\text { Holley } \\
\text { et al, } \\
2016^{31}\end{array}$ & $\begin{array}{l}\text { Reino } \\
\text { Unido }\end{array}$ & $\begin{array}{l}\text { Crianças na faixa etária entre } 2 \text { e } 4 \\
\text { anos de idade, amostra } n=90\end{array}$ & $\begin{array}{l}\text { Coorte } \\
\text { prospectivo }\end{array}$ & Nível 3 & $\begin{array}{l}\text { Questionário de práticas alimenta- } \\
\text { res abrangentes (CFPQ), Pesquisa } \\
\text { de temperamento EAS para crianças, } \\
\text { Questionário de comporta- } \\
\text { mento alimentar infantil (CEBQ) }\end{array}$ & $\begin{array}{l}\text { Pressão alimentar e modelagem } \\
\text { parental: Associação direta }\end{array}$ \\
\hline $\begin{array}{l}\text { Bennett } \\
\text { et al, } \\
2016^{35}\end{array}$ & $\begin{array}{l}\text { Reino } \\
\text { Unido }\end{array}$ & $\begin{array}{l}\text { Crianças entre a faixa etária de } 2 \text { a } 4 \\
\text { anos, com amostra } n=95\end{array}$ & Transversal & Nível 4 & $\begin{array}{l}\text { Questionário de Comportamento } \\
\text { Alimentar das Crianças (CEBQ), } \\
\text { Formulário padronizado refeição, e } \\
\text { Questionário de Práticas } \\
\text { Abrangentes de Alimentação (CFPQ) }\end{array}$ & $\begin{array}{l}\text { Monitoramento parental: Não } \\
\text { houve associação com o } \\
\text { comportamento alimentar da } \\
\text { criança }\end{array}$ \\
\hline $\begin{array}{l}\text { Russell } \\
\text { et al, } \\
2016^{27}\end{array}$ & $\begin{array}{l}\text { Estados } \\
\text { Unidos, } \\
\text { Europa e } \\
\text { México }\end{array}$ & $\begin{array}{l}\text { Crianças com faixa etária entre } 3 \text { e } 6 \\
\text { anos de idade, amostra } n=19444\end{array}$ & $\begin{array}{l}\text { Revisão } \\
\text { sistemática }\end{array}$ & Nível 1 & $\begin{array}{l}\text { Não relatou tipo de questionário } \\
\text { utilizado dos estudos incluídos }\end{array}$ & $\begin{array}{l}\text { Restrição e monitoramento } \\
\text { alimentar: Associação direta } \\
\text { com o comportamento } \\
\text { alimentar da criança }\end{array}$ \\
\hline $\begin{array}{l}\text { Tylka } \\
\text { et al, } \\
2016^{15}\end{array}$ & $\begin{array}{l}\text { Estados } \\
\text { Unidos }\end{array}$ & $\begin{array}{l}\text { Crianças entre as idades de } 2 \text { e } 5 \\
\text { anos, amostra } n=180\end{array}$ & Transversal & Nível 4 & $\begin{array}{l}\text { Questionário de alimentação infantil } \\
\text { (CFQ), Escala comer intuitivo (IES). }\end{array}$ & $\begin{array}{l}\text { Restrição alimentar: Associação } \\
\text { com o comportamento } \\
\text { alimentar da criança positiva }\end{array}$ \\
\hline $\begin{array}{l}\text { Steinsbekk } \\
\text { et al, } \\
2016^{16}\end{array}$ & Noruega & $\begin{array}{l}\text { Crianças na faixa etária ente } 2 \text { e } 8 \\
\text { anos de idade, amostra } n=3456\end{array}$ & $\begin{array}{l}\text { Coorte } \\
\text { prospectivo } \\
\text { não } \\
\text { experimental }\end{array}$ & Nível 3 & $\begin{array}{l}\text { Questionário de Comportamento } \\
\text { Alimentar das Crianças (CEBQ), } \\
\text { eQuestionário de Estilos de } \\
\text { Alimentação dos Cuidadores (CFSQ) } \\
\text { e Questionário de Pontos Fortes e } \\
\text { Dificuldades (SDQ) }\end{array}$ & $\begin{array}{l}\text { Pressão com o uso de força física } \\
\text { e restrição alimentar: Associação } \\
\text { direta com o comportamento } \\
\text { alimentar da criança }\end{array}$ \\
\hline $\begin{array}{l}\text { Blaine } \\
\text { et al, } \\
2017^{17}\end{array}$ & $\begin{array}{l}\text { Estados } \\
\text { Unidos }\end{array}$ & $\begin{array}{l}\text { Crianças em idade entre } 18 \text { meses e } \\
5 \text { anos, } n=693 \text { crianças avaliadas }\end{array}$ & $\begin{array}{l}\text { Revisão } \\
\text { sistemática,com } \\
\mathrm{n}=47 \text { artigos } \\
\text { incluídos na } \\
\text { pesquisa }\end{array}$ & Nível 1 & $\begin{array}{l}\text { Questionário Alimentação Infantil } \\
\text { (QFC), Questionário Práticas } \\
\text { Abrangentes da Alimentação (CFPQ) } \\
\text { e Questionário de Frequência } \\
\text { Alimentar (QFA) }\end{array}$ & $\begin{array}{l}\text { Restrição alimentar: Associação } \\
\text { direta } \\
\text { Pressão alimentar e monitora- } \\
\text { mento parental: Não houve } \\
\text { associação com o comporta- } \\
\text { mento alimentar da criança }\end{array}$ \\
\hline $\begin{array}{l}\text { Melo } \\
\text { et al, } \\
2017^{32}\end{array}$ & Brasil & $\begin{array}{l}\text { Crianças na faixa etária de } 1 \text { a } 5 \\
\text { anos de idade. Uma amostra } \mathrm{N}=95 \\
\text { de crianças. }\end{array}$ & Transversal & Nível 4 & $\begin{array}{l}\text { Escala de comportamento dos pais } \\
\text { durante a refeição (PMAS) }\end{array}$ & $\begin{array}{l}\text { Modelagem parental: } \\
\text { Associação direta com o } \\
\text { comportamento alimentar da } \\
\text { criança }\end{array}$ \\
\hline
\end{tabular}




\begin{tabular}{|c|c|c|c|c|c|c|}
\hline $\begin{array}{l}\text { Referência/ } \\
\text { Ano de } \\
\text { Publicação/ } \\
\text { País }\end{array}$ & Local & $\begin{array}{l}\text { Popul ação/ amostra/ } \\
\text { Faixa etária }\end{array}$ & $\begin{array}{c}\text { Delineamento } \\
\text { do estudo }\end{array}$ & $\begin{array}{l}\text { Nível de } \\
\text { evidência } \\
\text { científica }\end{array}$ & $\begin{array}{c}\text { Instrumento de avaliação } \\
\text { das práticas e comportamento } \\
\text { dos pais e das crianças }\end{array}$ & $\begin{array}{l}\text { Principais } \\
\text { Resultados }\end{array}$ \\
\hline $\begin{array}{l}\text { Byrne et al, } \\
2017^{18}\end{array}$ & Austrália & $\begin{array}{l}\text { Mães com idade } \geq 18 \text { anos e } \\
\text { crianças na faixa etária entre } 4 \\
\text { meses e } 1 \text { ano e } 4 \text { meses de idade, } \\
n=330 \text { participantes }\end{array}$ & Experimental & Nível 2 & $\begin{array}{l}\text { Questionário de Práticas e Estrutura } \\
\text { (FPSQ), Recordatório } 24 \mathrm{~h}, \\
\text { Questionário auto-administrado } \\
\text { contendo perguntas sobre comer } \\
\text { exigente e comportamento infantil }\end{array}$ & $\begin{array}{l}\text { Recompensar e restrição } \\
\text { alimentar: Associação direta } \\
\text { com o comportamento } \\
\text { alimentar da criança }\end{array}$ \\
\hline $\begin{array}{l}\text { Klazine et al, } \\
2017^{19}\end{array}$ & $\begin{array}{l}\text { Estados } \\
\text { Unidos }\end{array}$ & $\begin{array}{l}\text { Crianças faixa etária entre } 12 \text { a } 36 \\
\text { meses, } n=1005 \text { participantes }\end{array}$ & Transversal & Nível 4 & $\begin{array}{l}\text { Questionário Abrangente de } \\
\text { Práticas de Alimentação (CFPQ) e } \\
\text { Questionário de Comportamento } \\
\text { Alimentar das Crianças (CEBQ) }\end{array}$ & $\begin{array}{l}\text { Pressão alimentar com uso de } \\
\text { força e restrição alimentar: } \\
\text { Associação direta com o } \\
\text { comportamento alimentar da } \\
\text { criança }\end{array}$ \\
\hline $\begin{array}{l}\text { Haycraft } \\
\text { et al, } \\
2017^{46}\end{array}$ & $\begin{array}{l}\text { Reino } \\
\text { Unido }\end{array}$ & $\begin{array}{l}\text { Crianças na faixa etária de } 2 \text { a } 6 \\
\text { anos de idade, } n=437 \text { participan- } \\
\text { tes. }\end{array}$ & Transversal & Nível 4 & $\begin{array}{l}\text { Questionário Abrangente de } \\
\text { Práticas de Alimentação (CFPQ) e } \\
\text { Questionário de Comportamento } \\
\text { Alimentar das Crianças (CEBQ) }\end{array}$ & $\begin{array}{l}\text { Monitoramento Alimentar: } \\
\text { associação direta com o } \\
\text { comportamento alimentar da } \\
\text { criança. }\end{array}$ \\
\hline $\begin{array}{l}\text { Lindsay } \\
\text { et al, } \\
2017^{20}\end{array}$ & Ásia & $\begin{array}{l}\text { Crianças faixa etária entre dois a } 12 \\
\text { anos de idade, } \mathrm{N}=1782 \text { participan- } \\
\text { tes. }\end{array}$ & $\begin{array}{l}\text { Revisão } \\
\text { sistemática, } \\
\text { com } n=14 \text { artigos } \\
\text { elegidos }\end{array}$ & Nível 1 & $\begin{array}{l}\text { Questionário sobre Parentalidade } \\
\text { Alimentar (FPQ), Comportamento } \\
\text { Alimentar das Crianças (CEBQ) e } \\
\text { Questionário de alimentação infantil } \\
\text { (CFQ), Questionário de frequância } \\
\text { alimentar (QFA) e Recordatório } \\
\text { alimentar 24h }\end{array}$ & $\begin{array}{l}\text { Pressão com recompesas de } \\
\text { alimentos e restrição alimentar: } \\
\text { Associação direta com o } \\
\text { comportamento alimentar da } \\
\text { criança }\end{array}$ \\
\hline $\begin{array}{l}\text { Fries et al, } \\
2017^{30}\end{array}$ & $\begin{array}{l}\text { Estados } \\
\text { Unidos }\end{array}$ & $\begin{array}{l}\text { Crianças faixa etária entre } 12 \text { e } 36 \\
\text { meses, amostra } N=75 \text { crianças }\end{array}$ & $\begin{array}{l}\text { Coorte } \\
\text { prospectivo }\end{array}$ & Nível 3 & $\begin{array}{l}\text { Questionário de Estilos de } \\
\text { Alimentação dos Cuidadores (CFSQ), } \\
\text { : Questionário Abrangente de } \\
\text { Práticas de Alimentação } \\
\text { (CFPQ) e Comportamento Alimentar } \\
\text { das Crianças (CEBQ) }\end{array}$ & $\begin{array}{l}\text { Pressão com uso de força física } \\
\text { modelagem alimentar: } \\
\text { Associação direta }\end{array}$ \\
\hline $\begin{array}{l}\text { DeCosta } \\
\text { et al, } \\
2017^{21}\end{array}$ & Dinamarca & $\begin{array}{l}\text { Crianças faixa etária entre } 1 \text { e } 13 \\
\text { anos de idade, englobou um total } \\
\text { de } 120 \text { ensaios experimentais }\end{array}$ & $\begin{array}{l}\text { Revisão } \\
\text { sistemática, } \\
\text { com } \mathrm{N}=120 \\
\text { ensaios } \\
\text { experimentais. }\end{array}$ & Nível 1 & Grupos de intervenções & $\begin{array}{l}\text { Pressão alimentar com uso de } \\
\text { força física restrição e } \\
\text { recompensa alimentar: } \\
\text { Associação direta com o } \\
\text { comportamento alimentar da } \\
\text { criança }\end{array}$ \\
\hline $\begin{array}{l}\text { Powell et al, } \\
2017^{26}\end{array}$ & $\begin{array}{l}\text { Estados } \\
\text { Unidos }\end{array}$ & $\begin{array}{l}\text { Crianças na faixa etária pré-escolar } \\
\text { ( } 3 \text { a } 6 \text { anos de idade), abrangeu } \\
\text { uma amostra de } n=262\end{array}$ & Transversal & Nível 4 & $\begin{array}{l}\text { Questionário de Comportamento } \\
\text { Alimentar das Crianças (CEBQ), } \\
\text { Subescala emocional, Questionário } \\
\text { de Práticas de Alimentação e } \\
\text { Estrutura (FPSQ) e Questionário de } \\
\text { Autorregulação da Criança na } \\
\text { Alimentação. }\end{array}$ & $\begin{array}{l}\text { Recompensa alimentar: } \\
\text { Associação direta com o } \\
\text { comportamento alimentar da } \\
\text { criança }\end{array}$ \\
\hline $\begin{array}{l}\text { Jansen et al, } \\
2017^{34}\end{array}$ & Holanda & $\begin{array}{l}\text { Crianças entre a faixa etária de } 1 \frac{11 / 2}{} \\
\text { a } 6 \text { anos de idade, compreendeu } \\
\text { uma amostra de } n=4845\end{array}$ & $\begin{array}{l}\text { Coorte } \\
\text { prospectivo }\end{array}$ & Nível 3 & $\begin{array}{l}\text { Questionário de alimentação infantil } \\
\text { (CFQ), Checklist comportamento da } \\
\text { criança (CBCL), Questionário de } \\
\text { Comportamento Alimentar das } \\
\text { Crianças (CEBQ). }\end{array}$ & $\begin{array}{l}\text { Pressão alimentar: Associação } \\
\text { direta com o comportamento } \\
\text { alimentar da criança }\end{array}$ \\
\hline $\begin{array}{l}\text { Watterworth } \\
\text { et al, } \\
2017^{22}\end{array}$ & Canadá & $\begin{array}{l}\text { Amostra com } \mathrm{N}=31 \text { famílias, que } \\
\text { estivessem pelo menos uma } \\
\text { criança entre } 1 \text { ano e } 5 \text { meses a } 5 \\
\text { anos de idade. }\end{array}$ & $\begin{array}{l}\text { Coorte } \\
\text { prospectivo }\end{array}$ & Nível 3 & $\begin{array}{l}\text { Questionário Práticas Abrangentes } \\
\text { de Alimentação(CFPQ) e } \\
\text { Questionário NutriSTEP }\end{array}$ & $\begin{array}{l}\text { Recompensa alimentar: } \\
\text { Associação direta com o } \\
\text { comportamento alimentar da } \\
\text { criança }\end{array}$ \\
\hline
\end{tabular}

Dos 23 artigos integrantes dessa revisão, 61\% apresentaram associação direta entre as práticas parentais de restrição e aumento da ingestão alimentar pelas crianças, principalmente quando o alimento estava acessível, com consequente aumento do peso ${ }^{14-27}$. Trinta por cento das publicações identificaram associação significativa entre as práticas parentais de recompensa,alimentação seletiva do filho e comer na ausência de fome ${ }^{18,21-24,26}$.

No que se refere às práticas parentais de pressão alimentar com ameaças e imposição de punição, como retirada de brinquedos e sobremesas, caso o alimento não fosse consumindo, $43 \%$ das pesquisas mostraram uma diminuição da sensibilidade da criança ao sinal de saciedade 16-17,19-21,23-24,26,30. Em relação a modelagem parental,21,7\% dos estudos apontaram que quando os pais consumiam alimentos saudáveis em frente ou junto aos filhos, ensinavam, sobre os benefícios e sabores dos alimentos, ou quando aumentavam a exposição dos alimentos saudáveis, as crianças tinham um consumo aumentado de alimentos saudáveis, como frutas e verduras ${ }^{24,30-32,35}$. Além disso, entre os estudos que avaliaram as práticas de monitoramento parental, $13 \%$ demonstraram baixo consumo de alimentos não saudáveis como os alimentos 
ricos em açúcares e gorduras pelas crianças, e consequentemente um menor IMC 17,27,32.

Como medida de avaliação das práticas parentais, observou-se grande variabilidade dos instrumentos utilizados nos artigos incluídos. Dos estudos avaliados 23, (52\%) utilizaram o questionário de comportamento alimentar das crianças $(C E B Q)^{35},(43 \%)$ o questionário de práticas abrangentes de alimentação (CFPQ) ${ }^{36},(17 \%)$ o questionário de alimentação infantil (CFQ) ${ }^{37},(13 \%)$ o questionário de estilos de alimentação dos cuidadores (CFSQ) ${ }^{38},(9 \%) 0$ questionário de Práticas e Estrutura(FPSQ) ${ }^{39},(4 \%)$ a escala de neofobia alimentar infantil (CFNS) ${ }^{40},(4 \%)$ a escala de comportamento dos pais durante a refeição(PMAS) ${ }^{41},(4 \%)$ o questionário NutriSTEP ${ }^{42}$, (4\%) o questionário sobre parentalidade alimentar(FPQ) ${ }^{43}$, e (4\%) a escala do comer intuitivo(IES) ${ }^{44}$. Dentre os instrumentos utilizados, esses eram validados para a faixa etária de um a nove anos de idade, entretanto, somente o CFSQ avaliou o comportamento dos pais durante a refeição e o comportamento alimentar das crianças. Os demais mensuraram as múltiplas práticas de alimentação adotadas pelos pais com seus filhos.

Dos 23 artigos integrantes dessa revisão, $61 \%$ apresentaram associação direta entre as práticas parentais de restrição e aumento da ingestão alimentar pelas crianças, principalmente quando o alimento estava acessível, com consequente aumento do peso. Trinta por cento das publicações identificaram associação significativa entre as práticas parentais de recompensa,alimentação seletiva do filho e comer na ausência de fome.

Estudos de revisão sistemática, abrangendo um período de busca de 1980 a 2017, n = 22.039 participantes, foram realizados para analisar quais estratégias é comumente usado para mudar o comportamento alimentar das crianças e examinar como essas abordagens podem afetar o comportamento alimentar a curto e longo prazo. Observou-se que práticas parentais de recompensa, monitoramento, pressão alimentar com uso de força física e ameaças podem influenciar tanto de maneira positiva quanto negativa no comportamento alimentar da criança. No entanto, esses estudos desconsideraram variáveis importantes como nível socioeconômico e aleitamento materno ${ }^{17,20-21,28}$.

Klazine \& Ester ${ }^{19}$ realizaramum estudo transversal, nos Estados Unidos, abrangendo $\mathrm{n}=1005$ participantes entre a faixa etária de 12 a 36 meses. Evidenciou-se que pais superprotetores e autoritários que usam mais práticas de pressão para as crianças comerem alimentos saudáveis e restringem o consumo de alimentos não saudáveis para o controle de peso em crianças, essas têm um consumo excessivo de alimentos não saudáveis, quando os alimentos estão disponíveis $(p<0,001)$. As práticas parentais de monitoramento e modelagem demonstraram comportamentos alimentares mais saudáveis e consumo variado de alimentos pelas crianças $(p<0,03)$. No entanto, há várias limitações a serem consideradas nesse estudo, uma vez que, as variáveis socioeconômicas não foram exploradas, impossibilitando a análise do comportamento alimentar das crianças entre os níveis socioeconômicos.

Estudiosos averiguaram práticas parentais ${ }^{18}$, em um estudo experimental, na Austrália,com uma amostra de mães com idade $\geq 18$ anos e que tiveram parto a termo ( $\geq 37$ semanas de gestação e peso ao nascer $\geq 2.500 \mathrm{~g}$ ). Para asmães elegíveis foram solicitados dados quando os bebês tinham entre quatro e sete meses de idade, e posteriormente, quando as crianças tinham entre 12 e 16 meses de idade (junho de 2009 a junho de 2010). O estudo abordou como as práticas de alimentação não responsivas podem interferir na capacidade de uma criança reconhecer e atender a sinais de fome e saciedade e aumentar o risco de obesidade. Constatouse que a percepção materna sobre o paladar seletivo do filho esteve diretamente associada a 
quatro fatores: recompensa alimentar ( $p<0,001)$, recompensa por comportamento $(p<0,001)$, alimentação persuasiva ( $p<0,001)$ e restrição alimentar $p<0,001)$. É importante salientar que a percepção materna sobre o comportamento alimentar da criança, é limitada, quando uma mãe fica frustada com o filho, quando esse se recusa a comer, é possível que ela superestime esse comportamento.

Em outro estudo experimental, realizado por Remy et al. ${ }^{29}$, com crianças em idade pré-escolar (três a seis anos de idade), foi evidenciado que comida como recompensa foi a única prática de alimentação materna significativamente associada a criança comer na ausência da fome ( $p=$ 0,023). O comer na ausência da fome não foi relacionado a faixa etária, circunferência da cintura ou ao score $Z$ de IMC, mas foi maior meninos do que meninas $(p=0,006)$. Destaca-se que esse estudo, contemplou variáveis multivariadas, como idade, sexo, IMC, nível de escolaridade, raça e nível socioeconômico para realizar as associações entre práticas de alimentação materna e comportamento alimentar da criança.

Uma investigação do tipo transversal com 437 crianças, na faixa etária de dois a seis anos de idade, abordou as diferenças entre comportamentos alimentares de mães com peso saudável, com sobrepeso e obesidade. Concluiu-se, que independentemente do estado nutricional da mãe, houve práticas de modelagem e controle alimentar infantil $(p<0,001)$, e foi demonstrado que a modelagem parental materna associou-se ao consumo de alimentos saudáveis, como frutas e verduras, assim como as práticas maternas de controle à menor capacidade de resposta à saciedade pelas crianças. Não foram associadas as práticas de modelagem a outros membros da família, como pai ou irmãos, que podem ser modelos importantes para a ingestão de alimentos pelas crianças ${ }^{45}$.

Um estudo de coorte prospectivo, nos Estados Unidos com 75 crianças na faixa etária entre 12 e 36 meses, avaliou as práticas alimentares usadas pelos pais durante as refeições, bem como os comportamentos alimentares das crianças.Observou-se que apressão para comer, exercida pelos pais que não consumiam alimentos saudáveis foram associadas a uma alimentação mais seletiva pela criança $(p<0,001)$, enquanto que a modelagem parental, ou seja, os pais que alimentavam de maneira saudável, associaram-se a eficácia em convencer as crianças a comer alimentos saudáveis e ter dietas mais altas em frutas e legumes $(p<0,05)$. No entanto, uma limitação do estudo reside na natureza transversal da pesquisa, o que o torna limitado sobre a relação causa e efeito ${ }^{31}$.

Um estudo ${ }^{27}$ nos Estados Unidos, com delineamento transversal, envolvendo 262 crianças, na faixa etária pré-escolar (três a seis anos de idade), investigou as associações entre o uso dos alimentos pelos pais como recompensa, a auto-regulação para comer e comer em excesso na ausência da fome. A recompesa alimentar utilizada pelos pais foi associada significativamente às dificuldades para auto-regulação alimentar infantil $(p<0,001)$, sugerindo que níveis mais altos de recompensa parental através dos alimentos estão relacionados à baixa auto regulação alimentar pela criança. Também houve uma relação significativa entre o uso de recompensa alimentar parental e o comer emocional da criança, na ausência da fome $(p<0,001)$.É necessário destacar que este estudo baseou exclusivamente em questionários aplicados on-line, no qual as associações entre variáveis podem ter influência do método aplicado.

Jansen et al. ${ }^{34}$ em um estudo de coorte prospectivo, englobando 4845 crianças holandesas, entre um a seis anos de idade, avaliaram o comer compulsivo das crianças e a vontade de comer dos pais. Observaram que a prática parental de pressão para a criança se alimentar correlacionou- 
se positivamente com todas as avaliações, criança seletiva para comer, menor tempo de amamentação e comer na ausência de fome $(r=0,30)$, e associou-se positivamente com um menor IMC infantil $(p<0,001)$, ou seja, as crianças cujo os pais realizam práticas pressão para comer, essas tinham um menor IMC. Cabe ressaltar que esse estudo é fortalecido por sua grande amostra, além disso, utilizou um delineamento prospectivo com dados coletados em várias fases da avaliação, permitindo compreender os efeitos de longo prazo dos comportamentos alimentares das crianças e prática alimentares dos pais. Realizou-se outro estudo de coorte prospectivo, no Canadá com 31 famílias, que estivessem pelo menos uma criança na faixa etária de um a cinco anos de idade, e corroborou as associações entre práticas parentais de pressão e monitoramento aos filhos seletivos, ou seja, aqueles que tinham baixa ingestão de alimentos saudáveis ${ }^{21}$. Constatou-se a associação direta entre recompensas alimentares utilizadas pelas mães, aos filhos que recusavam comer alimentos saudáveis, e essas comerem na ausência de fome ( $p<0,001)$. Também foram encontradas associações entre práticas parentais de pressão com uso de força física e restrição alimentar aos filhos que rejeitavam comer alimentos saudáveis $(p=0,03)$, enquanto que as práticas parentais de modelagem foram associadas ao consumo aumentado de alimentos saudáveis pelas crianças $(p<0,001)$. Destaca-se que o estudo trabalhou com variáveis independentes, como as múltiplas práticas parentais em relação à alimentação infantil, e variáveis dependentes como nível socioeconômico, idade, sexo da criança, tempo de aleitamento materno e índice de massa corporal dos pais (IMC), no entanto, com uma amostra relativamente pequena de 31 crianças.

Verificou-se, em estudo transversal, contendo 192 crianças americanas, com faixa etária de sete a onze anos, que os comportamentos alimentares das crianças é um processo influenciado pelos fatores parentais e não parentais, como por exemplo, hábitos de assistir televisão e interferência de vizinhos ${ }^{23}$. Especificamente, mães com maiores IMCs tiveram correlação positiva $(r=0,20) a$ seus filhos consumirem menos grãos integrais. A restrição alimentar imposta pelos pais e uso de alimentos como recompensa foram diretamente relacionados com o consumo de salgadinhos, doces e refrigerantes $(p<0,05)$ e associados ao não consumo de frutas e vegetais $(p<0,05)$. Sobretudo, enfatiza-se que os participantes do estudo foram recrutados em uma comunidade online de pais, podendo não ser representativos os dados, em relação à população geral.

Investigação realizada no Reino Unido, através de um estudo de coorte, com 90 pais de crianças, entre dois e quatro anos de idade, avaliou se a responsabilidade alimentar das crianças estava associada aos métodos utilizadospelos pais à incentivarem o consumo de novos alimentos ${ }^{32}$. Observou-se que práticas parentais de pressão alimentar foram associadas a uma menor aceitação da criança a experimentar novos alimentos $(p<0,001)$, ou seja, práticas parentais de pressão alimentar eram exercidas a crianças seletivas para comer. Enquanto que a prática de comportamentos saudáveis pelos pais, como por exemplo, consumir mais vegetais foi relacionada diretamente com aceitação de novos alimentos pelos filhos $(p<0,02)$.No entanto, as variáveis analisadas foram idade da criança e conhecimento sobre nutrição dos pais, não correlacionando com nível socioeconômico e IMC dos pais, sendo que essas variáveis podem modificar o desfecho estudado.

Outra investigação explorou os efeitos moderadores do monitoramento no relacionamento entre impulsividade, comportamento alimentar e horário das ingestões das refeições, em um estudo transversal, abrangendo 95 pais e seus filhos com idade entre dois e quatro anos ${ }^{33}$. Os participantes foram recrutados através do banco de dados do Laboratório Infantil (ICL), provenientes de creches e grupos de crianças e em torno de Birmingham, Reino Unido. Os maiores níveis de impulsividade associaram positivamente a maiores taxas de monitoramento 
dos pais, no entanto, não houve associação entre impulsividade e monitoramento $(p=0,13)$. Maiores níveis de impulsividade foram associados com maior IMC, sendo que meninas com menor atividade motora tiveram menores escores $z$ do IMC ( $p<0,01)$. É importante ressaltar, que de acordo com o teste-t não houve diferenças de gênero na impulsividade, contudo, as variáveis sociodemográficas, aleitamento materno não foram analisadas.

Steinsbekk et al. ${ }^{16}$ por meio de um estudo longitudinal com 623 crianças norueguesas, em faixa etária escolar, examinaram prospectivamente as relações recíprocas entre o consumo variado de alimentos pelos pais e comportamentos alimentares de crianças. A maioria dos pais relataram altos níveis de incentivo para comer e controle alimentar, sendo esses associados significativamente ao comer em excesso pela criança $(p<0,01)$. Investigou-se,em outro trabalho, a associação entre a alimentação seletiva e o peso das crianças, tendo em conta o efeito moderador da prática da alimentação parental, emum estudo de coorte prospectivo, com 1024 crianças holandesas, com idade de cinco a nove anos ${ }^{36}$. Confirmou-se, que os pais considerados seletivos para comer eram mais propensos a pressionarem os seus filhos a comerem alimentos saudáveis e restringirem a ingestão de alimentos não saudáveis $(p<0,001)$, em comparação com os pais que não eram seletivos para comer. Embora a pesquisa tenha uma amostra grande e representativa, umdesenho prospectivo com análises multivariadas, salienta-se que as variáveis sociodemográficas não foram analisadas.

Autores ${ }^{15}$ analisaram a prática da alimentação restritiva utilizada pelas mães preocupadas com o peso de seus filhos para evitar o ganho de peso excessivo, em uma amostra de 180 crianças americanas. Averiguou-se que quando as mães tinham níveis de preocupação com o peso de seus filhos, essas exerciam práticas de restrição alimentar com os filhos $(p<0,01)$, assim, contribuindo para a preocupação da criança em relação aos alimentos restringidos, com conseqüência aumento do consumo e comer na ausência de fome. Destaca-se que o estudo investigou as variáveis tempo de aleitamento materno, IMC e nível de escolaridade materna, variáveis que subsidiam a relação práticas de alimentação materna e comportamento alimentar infantil. E crianças com maior IMC, que tiveram menor tempo de aleitamento materno, e mães com baixo nível de escolaridade associaram significativamente as práticas parentais de restrição alimentar $(p<0,01)$.

Em outro estudo transversal na Austrália, realizado por Russell et al. ${ }^{24}$ abordando os comportamentos usados pelos pais para influenciar as preferências alimentares de seus filhos na vida cotidiana, os pais do grupo saudável afirmaram que eles comiam persistentemente alimentos saudáveis na frente das crianças, já os pais do grupo insalubre relataram não comprar alimentos não saudáveis. As práticas parentais de recompensa alimentar associaram ao grupo insalubre, enquanto que a modelagem parental foi fortemente associada ao grupo saudável $(p<0,01)$, ou seja, os pais que consumiam alimentos saudáveis na frente ou junto com os filhos, que deixavam expostas uma variedade de alimentos saudáveis, as crianças tinham uma ingestão aumentada de alimentos saudáveis, como por exemplo, frutas e verduras. Ao contrário, as crianças em que os pais utilizavam práticas de recompensas, tinham um consumo reduzido de alimentos saudáveis. A pesquisa associou as variáveis mídia e comportamento alimentar das crianças, fatores importantes na escolha alimentar infantil. Uma grande pesquisa transversal, realizada em Londres por Susan et al. ${ }^{14}$, envolvendo 439 de crianças, na faixa etária entre três a seis anos de idade, avaliou uma série de diferentes comportamentos parentais, e observou que os filhos, cujos pais agiam de maneira menos autoritária em relação a ingestão alimentar tinham uma maior capacidade de resposta à saciedade $(p<0,01)$, enquanto que o monitoramento não teve uma associação positiva com a reposta à saciedade $(p<0,01)$.Os maiores níveis de escore 
$Z$ de IMC das crianças foram encontrados naquelas que alimentavam-se na ausência de fome $(p<0,01)$. Caracteriza-se uma limitação do estudo a não investigação das variáveis restrição, escolaridade e IMC materno, e nível socioeconômico, fatores que poderiam se associar com os estilos parentais e comportamento alimentar das crianças.

Revelou-se,em uma amostra de 301 crianças, com idade entre quatro a oito anos, que os comportamentos alimentares maternos altamente controladores estão associados com mais incentivos para comer, ou seja, comportamentos alimentares praticados pelos pais, como pressão para comer ou restrição alimentar, pode levar aos filhos a usarem comportamentos semelhantes ao interagir com seus irmãos, com consequente diminuição da saciedade e aumento de peso das crianças ${ }^{47}$. Enfatiza-se, que o estudo inclui apenas famílias de baixa renda, portanto, não se pode generalizar os dados para as famílias classificadas nos demais níveis socioeconômicos.

Explorando uma amostra de 432 pais de crianças, suecas, na faixa etária entre três a oito anos, pesquisadores analisaram um modelo de associações entre percepções parentais de comportamentos alimentares infantis entre pré-escolares e práticas alimentares parentais ${ }^{25}$. A análise das ligações entre comportamento alimentar da criança e práticas de alimentação dos pais revelou que pais preocupados com o peso de seus filhos são mais propensos às práticas de restrição alimentar ( $p<0,001$ ), em comparação com os pais que só percebem o seu filho como tendo um grande apetite, e não estão preocupados com o peso da criança. Também, houve uma associação entre as práticas parentais de pressão pelos pais preocupados com o peso do filho para as crianças comerem alimentos saudáveis $(p<0,001)$. As práticas de restrição e pressão alimentar utilizadas pelos pais provocaram um aumento do consumo de alimentos calóricos, ricos em gorduras e açúcar, e diminuição na ingestão de alimentos saudáveis, como frutas e verduras pelas crianças.No entanto, odelineamento transversal desta pesquisa não nos permite determinar a causalidade do fenômenos estudados.

Para avaliar a influência do comportamento dos pais durante a refeição e o excesso de peso na infância, Melo et al. ${ }^{32}$ em um estudo transversal, contendo 115 crianças brasileiras, entre um e quatro anos de idade, verificaram a relação entre ações dos pais durante as refeições e os hábitos alimentares das crianças com excesso de peso, e constataram associações no consumo de guloseimas, refeições especiais e excesso de peso entre as crianças ( $p<0,001)$. 0 estudo evidenciou que a maioria dos pais oferecem às crianças refeições diferentes da família, consomem refrigerantes e doces diariamente, e não oferece uma alimentação variada aos seus filhos.

Destaca-se nessa revisão que estratégias ou comportamentos são exercidos pelos pais com intuito de extinguir o comportamento alimentar inadequado e promover comportamentos alimentares adequados ${ }^{3}$.

\section{Discussão}

Essa revisão sistemática permite verificar que as atitudes exercidas pelos pais de restrição, pressão, recompensas, monitoramento, podem determinar o comportamento alimentar das crianças. No entanto, esses resultados precisam ser analisados com parcimônia, uma vez que a maior parte dos artigos trazem evidências de nível baixo a moderado ${ }^{13}$, e diversos deles desconsideraram 
variáveis importantes nas análises, como por exemplo, o nível socioeconômico, o aleitamento materno e a relação de pais e filhos especialmente durante as refeições.

A maioria dos artigos integrantes da presente revisão apresentavam desenhos do tipo transversal (53,2\%), definidos como nível 4 de evidência, trazendo limitações quanto ao consenso dos resultados analisados na presente investigação. Assim, destaca-se a importância de outros tipos de estudos, como os longitudinais e que considerem outros importantes variáveis como aleitamento materno e nível socioeconômico.

O aleitamento materno é importante determinante do comportamento alimentar, pois é um fator mediador para a auto regulação da fome e saciedade da criança ${ }^{47-48}$. Destaca-se que no Brasil a duração do aleitamento materno (AM) no Brasil é superior a vinte meses e a prevalência de aleitamento materno exclusivo (AME) em menores de seis meses é acima de $50 \%{ }^{49}$, sendo que em outros países como China e Estados Unidos o aleitamento materno é inferior a doze meses $^{50}$. Portanto, investigações nacionais sobre o tema devem considerar a amamentação entre as variáveis do estudo.

A literatura tem apontado que o poder de compra da população pode influenciar o consumo alimentar. A mudança de comportamento das famílias quanto a seus hábitos alimentares tem afetado as crianças, promovendo um maior consumo de alimentos com elevado valor energético, sódio e pobres em fibras, ferro e cálcio, associado à falta de atividade física. No mundo contemporâneo, onde os pais são ausentes, envolvidos no mercado de trabalho, tentam compensar essa ausência paternal com consumo de fast-foods ou com a compra de guloseimas. Além disso, a escassez de tempo incentiva a compra de alimentos de fácil e rápido preparo ${ }^{51}$.

O ambiente familiar pode ser considerado importante formador do comportamento e estilo de vida das crianças. É no âmbito familiar que se iniciam as primeiras experiências e aprendizagem alimentares $^{39}$. Alguns estudos mostram que os pais ou cuidadores responsáveis pela alimentação da família são facilitadores do consumo de alimentos não saudáveis pelas crianças. A mudança desse comportamento é desafiadora e implica na modificação dos hábitos alimentares de toda família, assegurando uma escolha saudável dos alimentos, acompanhado da prática de atividade física ${ }^{26,34,51}$.

No cenário contemporâneo da alimentação, as preferências

O ambiente familiar pode ser considerado importante formador do comportamento e estilo de vida das crianças. É no âmbito familiar que se iniciam as primeiras experiências e aprendizagem alimentares.

alimentares das famílias são voltadas para os alimentos que não demandam muito tempo de preparo e cocção e que sejam aderentes às suas condições socioeconômicas. Essas escolhas podem levar a uma alimentação desequilibrada com falta de nutrientes e excesso de sal, gorduras e açúcares ${ }^{49}$. Somado a isso, destaca-se o fato dos pais não serem os únicos fornecedores de alimentos para seus filhos, existindo outros ambientes, como creche e escolas, exercendo papel primordial nos primeiros anos de vida da criança, no que tange à construção de hábitos alimentares ${ }^{52}$.

Acredita-se que o contexto familiar contribui para preferências, rejeições e comportamentos alimentares. De fato, quando as intervenções nutricionais envolvem a família, têm-se melhores taxas de sucesso. O ambiente familiar tem repercussão significativa no comportamento alimentar, assim, os pais devem fornecer um modelo adequadodesse comportamento aos filhos, mesmo porque é na família em que se origina o padrão alimentar que pode durar toda a 
vida e esse padrão pode sofrer influências culturais ${ }^{51}$.

Nos últimos 60 anos, ocorreram mudanças econômicas, sociais e tecnológicas, que modificaram o estilo de vida da população em vários países, sendo que tais modificações alteraram também os comportamentos alimentares, influenciando de forma positiva ou negativa a saúde das pessoas $^{53}$. De fato, a tecnologia é um componente da atualidade que traz uma nova forma de viver a vida, tanto nos aspectos relacionais e hábitos de vida, provocando, muitas vezes um ambiente obesogênico marcado pelo sedentarismo, o consumo excessivo de hidratos de carbono e implicações emocionais ${ }^{54}$. Apesar disso, os artigos incluídos na presente revisão desconsideraram a variável tecnologia nos modelos causais do comportamento alimentar infantil, caracterizando-se uma importante limitação.

Um aspecto importante na presente revisão sistemática refere-se às práticas parentais relacionadas à superproteção e autoritarismo, que ocasionaram consumo excessivo de alimentos pelas crianças, além de que a recompensa alimentar provocou paladar seletivo e comer na ausência de fome entre os filhos. De fato, as práticas parentais de controle alimentar são estratégias comportamentais, utilizadas pelos pais, que influenciam diretamente a alimentação dos filhos, no sentido de aumentar ou diminuir a ingestão alimentar. A restrição de alguns alimentos, a pressão para comer, a recompensa com alimentos após ações positivas e ainda a disponibilidade e variedade dos alimentos em casa, podem afetar a preferência alimentar e auto regulação da criança, ou seja, alteram a capacidade de percepção dos sinais internos de fome e saciedade ${ }^{55}$.

As práticas de pressão alimentar e recompensas para os filhos comerem são as mais utilizadas pelos pais para aumentar a ingestão alimentar da criança, fazendo com que a criança coma tudo que está no prato, ou fazendo com que coma alimentos saudáveis, como frutas e verduras. No entanto, isso leva a perda ou diminuição dos sinais internos de saciedade, e a criança passa e utilizar os sinais externos, como comida preferida, cheiro da comida, ou as emoções como sinal de fome ou saciedade e consequentemente a criança começa a depender de estímulos externos para iniciar, manter e terminar sua refeição ${ }^{56}$.

As práticas parentais de restrição e monitoramento são ministradas à criança como uma forma de limitar a ingestão de alguns alimentos, principalmente os ricos em gorduras e açúcares. A utilização dessas práticas pode afetar negativamente ou positivamente a ingestão alimentar ou peso da criança, ou seja, restrição não parece produzir rejeição por parte da criança a determinado alimento, mas sim uma maior atração e consumo excessivo por este quando se torna disponível ${ }^{53}$. Acredita-se que essas práticas podem promover pensamentos contraditórios nas crianças, uma vez que os alimentos menos saudáveis, ricos em gorduras e açúcares são os mais restringidos, mas são habitualmente os mais consumidos em momentos agradáveis de socialização e celebração, em festas de aniversários, casamentos, jantares e almoços fora de $\operatorname{casa}^{57}$.

É importante ressaltar que as crianças aprendem sobre o alimento não somente vivenciando suas próprias experiências, mas observando os outros. Acredita-se que há similaridades entre pais e filhos com relação às preferências alimentares, aceitação e disposição em experimentar novos alimentos, sugerindo que os pais sejam os maiores exemplos de seus filhos. A modelagem parental pode se manifestar de várias maneiras, por meio da compra e preparo de alimentos saudáveis, ou através de seus comportamentos durante a refeição, como por exemplo, comer em família e ensinar sobre a importância do consumo de alimentos saudáveis ${ }^{58}$. De fato, essa 
revisão sistemática apontou que o modelo parental contribuiu para o consumo de alimentos saudáveis pelas crianças.

São inúmeros e complexos os fatores que contribuem para uma alimentação infantil adequada, considerando que a maneira de se alimentar está relacionada às emoções dos sujeitos envolvidos, em especial os pais. Nesse sentido, sugere-se que a forma como os pais interagem com seus filhos tem influência importante na formação dos seus hábitos alimentares ${ }^{59}$. A interação entre pais e filhos é um reflexo dos estilos educativos parentais adotados, comportamentos parentais, muitas vezes controversos, marcados por alto grau de dúvidas e aprendizagens. A maneira como se dá essa interação principalmente nos primeiros anos de vida tem o potencial de repercutir positiva ou negativamente na nutrição, crescimento e desenvolvimento da criança. Os pais reconhecerem e valorizarem os sinais de fome e saciedade que as crianças expressam, através da sinalização da fome e saciedade, contribui para a formação de um comportamento adequado $^{60}$.

Um estudo realizado por Carrozo et al. ${ }^{61}$ indicou que os pais exercem mais práticas parentais de pressão alimentar quando entre as práticas parentais de pressão alimentar com as crianças apresentam um baixo IMC e menor consumo de frutas e verduras, assim, na medida em que aumenta o IMC, diminui a pressão sentida para comer. Outro estudo realizado no México mostrou associações entre mães com comportamentos tolerantes e a oferta de alimentos ricos em gorduras e açúcares, contribuindo com a obesidade infantil ${ }^{62}$. Por outro lado, no estudo de Steinsbekk et al. ${ }^{16}$ verificou que a prática de restrição alimentar utilizada pelos pais foi um determinante para o controle de peso dos filhos.

Atualmente é um desafio estimular as crianças para que, ao final do primeiro ano de vida, realizem suas refeições junto com os demais membros da família, pois a alimentação em família é um hábito que vem se tornado cada vez mais escasso no mundo contemporâneo, onde os pais trabalham fora e têm pouco tempo para estar com os filhos. Outro acontecimento preocupante é que, com frequência, os pais e filhos, no momento em que estão em refeição juntos, têm sua atenção voltada para os programas de TV e ou manuseio de aparelhos eletrônicos ${ }^{63}$. Esse fato contribui para que os pais não dêem atenção à sinalização da saciedade das crianças, além de as propagandas veiculadas durante os horários das refeições, como almoço ou jantar, fomentarem o consumo de alimentos ricos em gorduras e açúcares e pobres em nutrientes, uma das razões pelas as quais a mídia, influencia o comportamento alimentar ${ }^{49,62}$.

Os mecanismos biológicos que regulam nosso apetite são complexos, dependem de vários estímulos e levam certo tempo para sinalizarem à saciedade, ou seja, comer devagar e com atenção, sem se envolver em outra atividade é uma boa maneira de controlar naturalmente o quanto comemos. Também é importante enfatizar que as características do ambiente em que comemos influenciam a quantidade de alimentos que ingerimos e o prazer que podemos aproveitar da alimentação, uma vez que, refeições feitas em família evitam que se coma rapidamente e controlam os estímulos da fome e saciedade. A participação de toda família, nas atividades de planejamento, preparo e aquisição dos alimentos, propicia momentos agradáveis de convívio entre os entes queridos, pois o envolvimento dos filhos na organização das refeições permite que eles conheçam novos alimentos e possam adquirir comportamentos alimentares saudáveis ${ }^{64}$.

A relação entre o comportamento alimentar dos pais durante a refeição e o comportamento alimentar dos filhos é complexa e escassa na literatura nacional. São necessárias investigações 
de natureza longitudinal com diversas variáveis explicativas no sentido de evidenciar essa relação e seus efeitos. Além disso,é sabido que o ambiente familiar está progressivamente mais envolvido na educação alimentar e comportamental das crianças ${ }^{65}$, motivo pelo qual estudos futuros deveriam analisar o papel destes.

Este artigo de revisão aponta algumas limitações, como a baixa qualidade da evidência dos trabalhos incluídos, em virtude, principalmente, do delineamento não transversal e de vários estudos apresentarem limitações metodológicas que comprometeram a qualidade da evidência Estudos de acompanhamento, com crianças brasileiras e que valorizem a multideterminação do comportamento alimentar infantil são necessários, permitindo o desenvolvimento de ações e programas de prevenção e mudança dos padrões alimentares infantis, contribuindo na promoção de saúde e prevenção das doenças crônicas não transmissíveis.

\section{Conclusão}

Os dados resultantes desta revisão sistemática permitem evidenciar que práticas parentais de pressão, restrição, recompensa e monitoramento alimentar podem determinar o comportamento alimentar de crianças. Estudos de acompanhamento, com crianças brasileiras e que valorizem a multideterminação do comportamento alimentar infantil são necessários, permitindo o desenvolvimento de ações e programas de prevenção e mudança dos padrões alimentares infantis, contribuindo na promoção de saúde e obesidade infantil.

Financiamento: O estudo não recebeu financiamento

Conflito de interesse: Os autores declaram não haver conflito de interesse

\section{Referências}

1. Vaz DSS, Bennemann RM. Comportamento alimentar e hábito alimentar: uma revisão. Revista UNINGÁ Review. 2014;20(1):108-112. https://www.mastereditora.com.br/periodico/20141001_083919.pdf

2. Klotz-Silva, J. Prado SD, Seixas CM. Hábitos alimentares e comportamento alimentar: do que estamos falando? Revista de Saúde Coletiva, Rio de Janeiro. 2016;26 (4): 1103-1123. https://doi.org/10.1590/s0103-73312016000400003

3. Carozzo NPP, Oliveira JHA. Práticas alimentares parentais: a percepção de crianças acerca das estratégias educativas utilizadas no condicionamento do comportamento alimentar. Psic Rev São Paulo. 2017;26(1):187-209. https://doi.org/10.23925/2594-3871.2017v26i1p.187-209

4. Rossi A, Moreira EAM, Rauen MS. Determinantes do comportamento alimentar: uma revisão com enfoque na família. Rev. Nutr., Campinas. 2008;21(6):739-748. https://doi.org/10.1590/S1415-52732008000600012

5. Alves MN, Muniz LC, Vieira MFA. Consumo alimentar entre crianças brasileiras de dois a cinco anos de idade: Pesquisa Nacional de Demografia e Saúde (PNDS), 2006. Ciênc Saúde Coletiva. 2013;18(11):3369-77. https://doi.org/10.1590/S1413-81232013001100026

6. Bortolini G, Vitolo M, Gubert M, Santos L. Iniquidades sociais influenciam a qualidade e a diversidade da dieta de crianças brasileiras de 6 a 36 meses. Cad Saúde Pública. 2015;31:241324. https://doi.org/10.1590/0102-311X00153414

7. Bernard F, Cichelero C, Vitolo MR. Comportamento de restrição alimentar e obesidade. Rev. Nutr., Campinas, 2005;18(1):85-93. https://doi.org/10.1590/S1415-52732005000100008 
8. Passos DR, Gigante DP, Maciel FV, Matijasevich A. Comportamento alimentar infantil: comparação entre crianças sem e com excesso de peso em uma escola do município de Pelotas, RS. Rev Paul Pediatr. 2015;33(1):42-9. https://doi.org/10.1016/j.rpped.2014.11.007

9. Moher D, Liberati A, Tetzlaff J, Altman DG, PRISMA Group. Preferred reporting items for systematic reviews and meta-Analyses: the PRISMA statement. PLoS Med 2009;21;6(7):e1000097. https://doi.org/10.1371/journal.pmed.1000097

10. Brasil. Ministério da Saúde. Secretaria de Ciência, Tecnologia e Insumos Estratégicos Departamento de Ciência e Tecnologia. Diretrizes Metodológicas. Elaboração de revisão sistemática e metanálise de estudos observacionais comparativos sobre fatores de risco e prognóstico - Brasília: Ministério da Saúde, 2014. http://bvsms.saude.gov.br/bvs/ publicacoes/diretrizes_metodologicas_elaboracao_sistematica.pdf

11. Ministério da Saúde (BR). Secretaria de Atenção à Saúde. Departamento de Atenção Básica. Protocolos do Sistema de Vigilância Alimentar e Nutricional - SISVAN na assistência à saúde. Brasília: Ministério da Saúde [Internet]. 2008; [cited 2017 Jan 17]; 64 p. Available from: http://189.28.128.100/nutricao/docs/geral/orientacoes_basicas_sisvan.pdf

12.Tosatti AM, Ribeiro IW, Machado RHV, Maximino P, Bozzini AB, Ramos CC, Fisberg M. Fazer refeições em família tem efeito protetor para a obesidade e bons hábitos alimentares na juventude? Revisão de 2000 a 2016. Rev. Bras. Saúde Matern. Infant. 2017;17(3):435-445 https://doi.org/10.1590/1806-93042017000300002

13.Agency for Health Care Research and Quality (AHRQ) [homepage on the Internet]. Quality indicators [cited 2018 Mar 25]. Available from: http://www.qualityindicators.ahrq.gov

14.Susan CPHD, Leora BMS, Elissa DBS, Laura KMP.Parent Feeding Behavior and Child. Apetite: Associations Depend on Feeding Style. Int J Eat Disord. 2014;47(7):705-709. https://doi.org/10.1002/eat.22324

15.Tylka TL, Lumeng JC, Eneli IU. Maternal Intuitive Eating as a Moderator of the Association between Concern about Child Weight and Restrictive Child Feeding. Apetite. 2015; 95:158165. https://doi.org/10.1016/j.appet.2015.06.023

16.Steinsbekk S, Belsky J, Wichstrøm L. Parental Feeding and Child Eating: An Investigation of Reciprocal Effects. Child Dev. 2016;87(5):1538-1549. https://doi.org/10.1111/cdev.12546

17. Blaine RE, Kachurak U, Davison KK, Klabunde R, Fisher JO. Food parenting and child snacking: a systematic review. Int J BehavNutrPhysAct. 2017;14(1):146. https://doi.org/10.1186/s12966-017-0593-9

18. Byrne R, Jansen E, Daniels L. Perceived fussy eating in Australian children at 14 months of age and subsequent use of maternal feeding practices at 2 years. Int J BehavNutrPhysAct. 2017;14(1):123. https://doi.org/10.1186/s12966-017-0582-z

19.Klazine VDH, Ester FCS. Parenting styles, feeding styles and foodrelated parenting practices in relation to toddlers' eating styles: A cluster-analytic approach. PLoS One. 2017;12(5):e0178149. https://doi.org/10.1371/journal.pone.0178149

20.Lindsay AC, Sitthisongkram S, Greaney ML, Wallington SF, Ruengdej P. Non-Responsive Feeding Practices, Unhealthy Eating Behaviors, and Risk of Child Overweightand Obesity in Southeast Asia: A Systematic Review. Int J Environ Res Public Health. 2017;14(4):E436.

https://doi.org/10.3390/ijerph14040436

21.DeCosta P, Moller P, Frst MB, Olsen A. Changing Children's eating behaviour - A review of experimental research. Apetite. 2017;113:327-357.

https://doi.org/10.1016/j.appet.2017.03.004

22. Watterworth JC, Hutchinson JM, Buchholz AC, Darlington G, Randall Simpson JA, Ma DWL, Haines J, Guelph Family Health Study.Food parenting practices and their association with child nutrition risk status: comparing mothers and fathers.ApplPhysio/NutrMetab. 42(6):667-671. https://doi.org/10.1139/apnm-2016-0572 
23.Hoffmann DA, Marx JM, Kiefner-Burmeister $U$, Musher-Eizenman DR.Influence of maternal feeding goals and practices on children's eating behaviors. Apetite. 2016 107:21-27. https://doi.org/10.1016/j.appet.2016.07.014

24. Russell CG, Worsley A, Campbell KJ. Strategies used by parents to influence their children's food preferences. Apetite. 2015;90:123-130. https://doi.org/10.1016/j.appet.2015.02.038

25. Antoniou EE, Roefs A, Kremers SP, Jansen A, Gubbels JS, Sleddens EF, Thijs C. Picky eating and child weight status development: a longitudinal study. J Hum Nutr Diet 2016; 29(3):298-307. https://doi.org/10.1111/jhn.12322

26. Anna EK, Kimmo S, Karin ELI, Louise L, Jonna N, Claude M, Paulina N. Associations between Parental Concerns about Preschoolers' Weight and Eating and Parental Feeding Practices: Results from Analyses of the Child Eating Behavior Questionnaire, and the Lifestyle Behavior Checklist. PLoS One. 2016;11(1):e0147257. https://doi.org/10.1371/journal.pone.0147257

27. Russell CG, Taki S, Laws R, Azadi L, Campbell KJ, Elliott R, Lynch J, Ball K, Taylor R, Denney-Wilson E. Effects of parent and child behaviours on overweight and obesity in infants and young children from disadvantaged backgrounds: systematic review with narrative synthesis. BMC Public Health. 2016;16:151. https://doi.org/10.1016/j.appet.2015.02.038

28. Powell EM, Frankel LA, Hernandez DC. The mediating role of child self-regulation of eating in the relationship between parental use of food as reward and child emotional overeating. Apetite. 2017;113:78-83. https://doi.org/10.1016/j.appet.2017.02.017

29. Remy E, Issanchou S, Chabanet C, Boggio V, Nicklaus S. Impact of adiposity, age, sex and maternal feeding practices on eating in the absence of hunger and caloric compensation in preschool children. Int J Obes. 2015;39(6):925-930. https://doi.org/10.1038/ijo.2015.30

30.Fries LR, Martin N, van der Horst K. Parent-child mealtime interactions associated with toddlers' refusals of novel and familiar foods. PhysiolBehav2017;176:93-100.

https://doi.org/10.1016/j.physbeh.2017.03.001

31. Holley CE, Farrow C, Haycraft E. Investigating the role of parent and child characteristics in healthy eating intervention outcomes. Apetite. 2016;105:291-297. https://doi.org/10.1016/j.appet.2016.05.038

32. Melo KM, Cruz ACP, Brito MFSF, Pinho L. Influência do comportamento dos pais durante a refeição e no excesso de peso na infância. Esc Anna Nery. 2017;21(4):e20170102. https://doi.org/10.1590/2177-9465-ean-2017-0102

33.Palfreyman Z, Haycraft E, Meyer C. Development of the Parental Modelling of Eating Behaviours Scale (PARM): links with food intake among children and their mothers. Matern Child Nutr. 2014;10(4):617-629. https://doi.org/10.1111/j.1740-8709.2012.00438.x

34.Jansen PW, de Barse LM, Jaddoe VW, Verhulst FC, Franco OH, Tiemeier H. Bi-directional associations between child fussy eating and parents' pressure to est: Who influences whom?. Physiol Behav. 2017:176;101-106. https://doi.org/10.1016/j.physbeh.2017.02.015

35. Bennett C, Blissett J. Parental monitoring may protect impulsive children from overeating. PediatrObes. 2017;12(5):414-42. https://doi.org/10.1111/ijpo.12159

36.Carnell S, Wardle J. Measuring behavioural susceptibility to obesity: Validation of the child eating behaviour questionnaire. Apetite. 2007;48:104-113.

https://doi.org/10.1016/j.appet.2006.07.075

37. Musher-Eizenman D, Holub S. Comprehensive feeding pratices questionnaire: validation of a new measure of parental feeding pratices. J PediatrPsychol. 2007;32(8):960-972.

https://doi.org/10.1093/jpepsy/jsm037

38. Birch LL, Fisher JO, Grimm-Thomas K, CN Markey, Sawyer R, Johnson SL. Confirmatory factor analysis of the Child Feeding Questionnaire: a measure of parental attitudes, beliefs and practices about child feeding and obesity proneness. Apetite. 2001;36(3):201-210.

https://doi.org/10.1006/appe.2001.0398 
39.Wardle J, Guthrie CA, Sanderson S, Rapoport L. Development of the childrens eating behavior questionnaire. J Child Psychol Psychiatry 2001;42:(7)963-970.

https://doi.org/10.1111/1469-7610.00792

40.Jansen E, Williams KE, Mallan KM, Nicholson JM, Daniels L. The feeding practices and structure questionnaire (FPSQ-28): a parsimonious version validated for longitudinal use from 2-5 years. Apetite. 2016;100:172-180. https://doi.org/10.1016/j.appet.2016.02.031

41.Pliner P. Development of measures of food neophobia in children. Apetite. 1994; 23(2):147163. https://doi.org/10.1006/appe.1994.1043

42.Tylka TL. Development and psychometric evaluation of a measure of intuitive eating. $J$ SocActionCounsPsychol. 2006;53:226-240. https://doi.org/10.1037/0022-0167.53.2.226

43.Randall Simpson JA, Keller HH, Rysdale LA, Beyers JE.Nutrition Screening Tool for Everry Preschooler (NutriSTEP ${ }^{\circledR}$ ): validation and teste-retest reliability of a parent-adminidtered questionnaire assessing nutrition risk of prechoolers. Eur J ClinNutr. 2008; 62(6):770-780. https://doi.org/10.1038/sj.ejcn.1602780

44.Steptoe A, Pollard TM, Wardle J. Development of a the motives underlying the selection of food: the food choice questionnaire. Apetite. 1995; 25(3):267-284.

https://doi.org/10.1006/appe.1995.0061

45.Tribole E, Resch E. Intuitive eating: A revolutionary program that works. 3rd. New York: St. Martin's Press; 2012. Apetite. 2015;95:158-165. https://doi.org/10.1016/j.appet.2015.06.023

46.Haycraft EMMA, Karasouli E, Meyer C. Maternal feeding practices and children's eating behaviours: A comparison of mothers with healthy weight versus overweight/ obesity. Apetite. 2017;116:395-400. https://doi.org/10.1016/j.appet.2017.05.033

47.Mosli RH, Miller AL, Peterson KE, Lumeng JC. Sibling Feeding Behavior: Mothers as Role Models During Mealtimes. Apetite. 2016;96:617-620.

https://doi.org/10.1016/j.appet.2015.11.006

48.Camaduro SP, Oliveira DV, Bennemann RM, Silva SE, Antunes MD, Júnior JRAN, Gonçalves JE. Associação entre o nível socioeconômico e o consumo alimentar de criança com idade escolar matriculadas na rede pública de ensino do município de Maringá-PR. Cinergis. 2017; 18(2):125-128. https://doi.org/10.17058/cinergis.v18i2.8753

49.Boccolinii CS, Boccolinii PMM, Monteiro FR, Venâncio SI, Giugliani ERJ. Tendência de indicadores do aleitamento materno no Brasil em três décadas. RevSaude Publica. 2017;51:108. https://doi.org/10.11606/S1518-8787.2017051000029

50.Rollins NC, Lutter CK, Bhandari N, Hajeebhoy N, HortonS, Martines JC, Piwoz EG, Richter LM, Victora CG. Por que investir e o que será necessário para melhorar as práticas de amamentação? Epidemio/Serv Saúde. 2016;25(1):25-44.

http://scielo.iec.gov.br/pdf/ess/v25n1/Amamentacao2.pdf

51.Dantas RR, Silva GAP. O papel do ambiente obesogênico e dos estilos de vida parentais no comportamento alimentar infantil. RevPaul Pediatr 2019;1-9.

http://www.scielo.br/pdf/rpp/2019nahead/pt_0103-0582-rpp-2019-37-3-00005.pdf

52. Kiefner-Burmeister AE, Hoffmann DA, Meers MR, Koball AM, Musher-Eizenman DR. Food consumption by young children: a function of parental feeding goals and practices. Apetite. 2014;74:6-11. https://doi.org/10.1016/j.appet.2013.11.011

53. Onis M. Preventing childhood overweight and obesity. J Pediatr (Rio J). 2015;91:105-7. https://doi.org/10.1016/j.jped.2014.10.002

54.Fisberg M, Maximinoc P, Kaind J, Kovalskys I. Obesogenic environment - intervention opportunities.JPediatr(Rio J). 2016;92(3):S30-S39. https://doi.org/10.1016/j.jped.2016.02.007

55. Farrow CV, Haycraft E, Blissett JM. Teaching our children when to eat: how parental feeding practices inform the development of emotional eating-a longitudinal experimental design. Am J ClinNutr. 2015;101(5):908-913. https://doi.org/10.3945/ajcn.114.103713 
56.Vandeweghe L, Verbeken S, Vervoort L, Moens E, Braet C. Reward sensitivity and body weight: the intervening role of food responsive behavior and external eating. Apetite. 2017;112:150-156. https://doi.org/10.1016/j.appet.2017.01.014

57.Larsen JK, Hermans RC, Sleddens EF, Engels RC, Fisher JO, Kremers SP. How parental dietary behavior and food parenting practices affect children's dietary behavior. Interacting sources of influence?. Apetite. 2015;89:246-257. https://doi.org/10.1016/j.appet.2015.02.012

58.Silva GA, Costa KA, Giugliani ER. Infant feeding: beyond the nutritional aspects. J Pediatr (Rio J). 2016;92(3 Suppl 1):S2-S7. https://doi.org/10.1016/j.jpedp.2016.03.015

59.Costa KAO, Antunes MMC, Cabral PC, Silva GAP. Feeding style of adolescente mothers and complementary feeding practice of their infants. Rev Nutri. 2018;31(1):49-58. https://doi.org/10.1590/1678-98652018000100005

60.Alvarenga P, Malhado SCB, Lins TCS. Responsividade e práticas de socialização maternas. J Psicol. 2014;19(4):305-314. https://doi.org/10.1590/S1413-294X2014000400008

61.Carrozo NPP, Oliveira JHA. Comportamento alimentar: um estudo da relação entre IMC de crianças e sua percepção sobre as práticas alimentares parentais. Est Inter Psicol. 2015;6(1):2135. https://doi.org/10.5433/2236-6407.2015v6n1p21

62.Chaidez V, McNiven S, Vosti SA, Kaiser LL. Sweetened food purchases and indulgent feeding are associated with increased toddler antropometry. J NutrEducBehav 2013;21(4):16. https://doi.org/10.1016/j.jneb.2013.05.011

63.Thompson AL, Bentley ME. The critical period of infant feeding for the development of early disparities in obesity. Social Science \& Med. 2013;97:288-296. https://doi.org/10.1016/j.socscimed.2012.12.007

64.Brasil. Ministério da saúde. Secretaria de atenção à saúde. Departamento de Atenção Básica. Guia alimentar para a população brasileira / Ministério da Saúde, Secretaria de Atenção à Saúde, Departamento de Atenção Básica. - 2. ed. - Brasília: Ministério da Saúde, 2014;156:il. http://bvsms.saude.gov.br/bvs/publicacoes/guia_alimentar_populacao_brasileira_2ed.pdf

65.Huçalo AP, Ivatuik AL. A relação entre práticas parentais e o comportamento alimentar em crianças. Revista PsicoFAE. 2017;6(2):113-128.

https://revistapsicofae.fae.edu/psico/article/view/141 